comment on the article, published in the same issue of NATURE, and intended to be read in conjunction therewith. Its purpose was to direct attention to the Supplement and to indicate its general tendency. It was obviously impossible and undesirable to mention all Dr. Jeans's suggestions about life. Those suggestions, indeed, were entirely secondary to the main thesis, which was that "the primary physical process of the universe is the conversion of matter into radiation." The possible view of life referred to in the note was selected because it threw the main thesis into the strongest relief. The selection carried no implication whatever that the view was the one favoured by Dr. Jeans or by modern scientific thought. As Mr. Robinson says: "readers can turn to the original ... and judge for themselves." In case Mr. Robinson imagines that there has been an insidious attempt to propagate materialism in the guise of science, let me say that personally I hold the idealistic view-so strongly, indeed, as to be able to contemplate the alternative with equanimity.

It may possibly save further misunderstanding if this opportunity is taken of correcting two misprints in the original notes. In line 3 of the first paragraph, "contributions " should be " constitution," and in line 4 of the second paragraph, "testing" should be "tasting."

THE WRITER OF THE NOTES.

\section{The Action of Silica on Electrolytes.}

THE importance of this subject in chemistry and pedology is my excuse for a further letter in reply to that of Prof. Mukherjee in NATURE of October 9. I could wish that he had told us more as to the method by which he demonstrates 'primary adsorption,' as until it is established-and this is the point of disagreement between us-it is scarcely worth while discussing its mechanism. I have now tried so many variations of the experiment in attempting without success to obtain Prof. Mukherjee's results, that I am a little discouraged, and this the more because the magnitude of the effects described in successive communications has been greatly reduced. Thus the early statement that considerable quantities of acids could be adsorbed by silica was modified by his letter in NATURE (January 3I, I925) stating that the silica used contained alkali. Again, in the issue of April 4, I925, it was stated that Io grams silica adsorbed 42 c.c. of decinormal hydrochloric acid, i.e. $250 \times 10^{-4}$ gram molecules of acid per gram molecule of silica. But in the letter under reply, this 250 has been reduced to $I$.

In the letter of January $3 \mathrm{I}, \mathrm{1925}$, it is stated that the $p H$ value hydrochloric acid rose from 3.4 to 4.6 by passage through air-dried silica. We tried mixing pure silica with acid of this strength and found the $p H$ values to be 3.45 before and 3.46 after the addition of the silica, results well within the experimental error.

It is most desirable that this question should be settled definitely. I would willingly try further direct experiments on mixing silica with acid if Prof. Mukherjee would tell me the strengths and quantities which must be taken to be sure of obtaining his results. Meanwhile, I am of the opinion that silica does not adsorb acids.

A. F. Joseph.

Wellcome Tropical Research Laboratories, Khartoum, November 3 .

\section{"Colloid Chemistry."}

REFERRING to the review of vol. I of "Colloid Chemistry: Theoretical and Applied," which appeared in NATURE of October 23, p. 585 , three references to electrodialysis are given in the book on p. 937, ultrafiltration dialysis is treated on p. 832 , and electroultrafiltration on p. 834 et seq., where a foot-note states that Dr. P. H. Prausnitz' paper on electroosmosis (Graf Botha Schwerin, etc.) will appear in vol. 3. It has so many descriptions of practical applications, that it justly belongs in the volume on technology. Diffusion is, furthermore, treated in the latter part of Svedberg's paper on centrifugal and diffusion methods for the study of dispersity and hydration in sols, and in papers by Liesegang, Bradford, and Holmes; and as Liesegang says, p. 784 , " dialysis is practically the same thing as diffusion in jellies, only it permits us to recognise more distinctly the processes going on inside of the membrane." It would seem, then, that dialysis has more than "casual mention in two places," and that electrodialysis is not "neglected," even though neither is given elementary discussion. 5o East 4ist Street,

New York City, November I $_{5}$.

THE process of dialysis is so widely used for the purification of colloids that one would expect to find some general treatment of it in a book of this size dealing with 'theory and methods.' Diffusion into jellies, or without a septum, is not dialysis, nor are these methods used to any extent for the removal of non-colloidal substances. Similarly, the scattered references to electrodialysis are no substitute for a systematic treatment, nor is the promise of an article, in a future volume, on electro-osmosis, which is a different phenomenon. P. C. L. THORNe.

\section{The 'Bleeding' of Trees through Injury.}

MORE than two years ago there was a short correspondence in NATURE (II3, pp. 492 and 604) on the 'bleeding' of trees in the spring through injury. The trees especially mentioned were the sycamore and birch. It may be of interest to record the fact that the common walnut (Juglaus regia) may be included among the "bleeders - at any rate, the specimen I have had under observation behaved markedly so. Casually severing a twig of this tree in mid-spring, I925, I was a little surprised to find that sap immediately exuded. On February $\mathrm{I}$ last this tree for certain reasons had reluctantly to be felled. As the walnut is late in coming into leaf and adapted to a climate warmer than Cumberland can afford it, it was scarcely to be expected that so early in the year there would have been any exudation of sap. My surprise therefore was great to find such an outflow, on the application of the crosscut-saw to the base of the trunk, as to cause the sawdust to become quite moist. In addition, as the woodmen lopped off the branches of the felled tree, sap issued so freely from the cut surfaces that it could have been collected.

The tree still further astonished me, for throughout the spring, summer, and early autumn, sap exuded copiously from the stump, making the soil around quite soppy. Micro-organisms of one kind or another revelled in the exudation and gave rise to a sickly stench. This during a spell of warm weather became so obnoxious that the surface of the stump had to be cleaned, dried, and disinfected. The outflow still continued after the treatment, and appears only to have stopped through the setting-in of the cold weather of October.

I have never noticed such a long-sustained bleeding in the case of the stools of the sycamore or birch. These, however, usually sucker, and the sap may be utilised in this way, thus preventing any visible outflow. The walnut stump in question has shown no signs of sending up sucker-shoots.

Blaithwaite, Wigton, Cumberland, JOHN PARKIN.

$$
\text { NO. 298I, VOL. I I } 8 \text { ] }
$$

